\title{
Ion-Isotopic Exchange Reaction Kinetics using Anion Exchange Resins Dowex 550A LC and Indion-930A
}

\author{
P.U. Singare*
}

Department of Chemistry, Bhavan's College, Munshi Nagar, Andheri (West), Mumbai 400 058, India

\begin{tabular}{l}
\hline C H R O N I C L E \\
\hline Article history: \\
Received January 22, 2014 \\
Received in revised form \\
February 02, 2014 \\
Accepted 8 May 2014 \\
Available online \\
9 May 2014 \\
\hline Keywords: \\
Ion exchange resins \\
Dowex 550A LC \\
Indion-930A \\
${ }^{131}$ I \\
${ }^{82}$ Br \\
Tracer isotopes \\
Reaction kinetics \\
Ion-isotopic exchange
\end{tabular}

\begin{abstract}
A B S T R A C T
The present paper deals with the characterization of ion exchange resins Dowex 550A LC and Indion-930A based on kinetics of ion-isotopic exchange reactions for which the short lived radioactive isotopes ${ }^{131} \mathrm{I}$ and ${ }^{82} \mathrm{Br}$ were used as a tracers. The study was performed for different concentration of ionic solution varying from $0.001 \mathrm{~mol} / \mathrm{L}$ to $0.004 \mathrm{~mol} / \mathrm{L}$ and temperature in the range of $30.0{ }^{\circ} \mathrm{C}$ to $45.0{ }^{\circ} \mathrm{C}$. The results indicate that as compared to bromide ion-isotopic exchange reaction, iodide exchange reaction take place at the faster rate. For both the ionisotopic exchange reactions, under identical experimental conditions, the values of specific reaction rate increases with increase in the ionic concentration and decreases with rise in temperature. It was observed that at $35.0^{\circ} \mathrm{C}, 1.000 \mathrm{~g}$ of ion exchange resins and $0.002 \mathrm{~mol} / \mathrm{L}$ labeled iodide ion solution for iodide ion-isotopic exchange reaction, the values of specific reaction rate $\left(\mathrm{min}^{-1}\right)$, amount of ion exchanged $(\mathrm{mmol})$, initial rate of ion exchange $(\mathrm{mmol} / \mathrm{min})$ and $\log \mathrm{K}_{\mathrm{d}}$ were $0.270,0.342,0.092$ and 11.8 respectively for Dowex 550A LC resin, which was higher than the respective values of $0.156,0.241,0.038$ and 7.4 as that obtained for Indion930A resins. From the results, it appears that Dowex 550A LC resins show superior performance over Indion-930A resins under identical experimental conditions.
\end{abstract}

\section{Introduction}

Applications of radiotracers in chemical research cover the studies of reaction mechanism, kinetics, exchange processes and analytical applications such as radiometric titrations, solubility product estimation, isotope dilution analysis and autoradiography. The choice of the radioisotope and the physical and chemical property of the radiotracer to be used will depend on the nature of the study. In radiotracer study, a short lived radioisotope in a physico-chemical form similar to that of the process material is used to trace the material under study. The tracer concentration recorded at various locations is analyzed to draw information about the dynamic behavior of the system under study. Industrial applications of radioisotopes ensure good quality products and bring down the cost of manufacture by ways of sensitive non-destructive testing and efficient in-process control.

\footnotetext{
* Corresponding author. Fax: + 9122 26256453; Tel: + 9122 26256451/ 52

E-mail address: pravinsingare@gmail.com (P.U. Singare) 
Radiotracers have helped in identification of leaks in buried pipelines and dams. Process parameters such as mixing efficiency, residence time, flow rate, material inventory and silt movement in harbours are studied using radioisotopes ${ }^{1}$. The efficiency of several devices in a wastewater treatment plant (primary and secondary clarifiers, aeration tank) is investigated by means of radiotracers ${ }^{2}$. Radioisotopes are also employed in certain manufacturing processes to induce desired chemical reactions ${ }^{1}$. Thus radioisotopes have become useful tool and almost every branch of industry uses them ${ }^{1}$. The radioisotopes in suitable physical and chemical forms are introduced in systems under study. By monitoring the radioactivity both continuously or after sampling (depending on the nature of study), the movement, adsorption, retention etc. of the tracer and in turn, of the bulk matter under investigation, can be followed. Radiotracer methodology is described extensively in the literature ${ }^{2-9}$.

Considering the extensive technological application of radioactive tracers, in the present investigation, attempts are made to assess the performance of Dowex 550A LC (nuclear grade) and Indion-930A (non-nuclear grade) ion exchange resins under different experimental conditions by application of tracer technique.

\section{Experimental}

\subsection{Conditioning of ion exchange resins}

Dowex 550A LC is a Type I strong base, quaternary ammonium, nuclear grade anion exchange resins in hydroxide form (by Dow Chemical Company, Midland, Michigan) while Indion-930A is a macroporous Type I, strong base anion exchange resin in chloride form (by Ion Exchange India Ltd., Mumbai). Details regarding the properties of the resins used are given in Table 1. These resins were converted separately in to iodide / bromide form by treatment with $10 \% \mathrm{KI} / \mathrm{KBr}$ solution in a conditioning column which is adjusted at the flow rate as $1 \mathrm{~mL} / \mathrm{min}$. The resins were then washed with double distilled water, until the washings were free from iodide/bromide ions as tested by $\mathrm{AgNO}_{3}$ solution. These resins in bromide and iodide form were then dried separately over $\mathrm{P}_{2} \mathrm{O}_{5}$ in desiccators at room temperature.

Table 1. Properties of ion exchange resins

\begin{tabular}{ccccccc}
\hline Ion exchange resin & Matrix & $\begin{array}{c}\text { Functional } \\
\text { Group }\end{array}$ & $\begin{array}{c}\text { Particle } \\
\text { Size } \\
(\mathrm{mm})\end{array}$ & $\begin{array}{c}\text { Moisture } \\
\text { Content } \\
(\%)\end{array}$ & $\begin{array}{c}\text { Operating } \\
\mathrm{pH}\end{array}$ & $\begin{array}{c}\text { Maximum } \\
\text { operating } \\
\text { temperature } \\
\left({ }^{\circ} \mathrm{C}\right)\end{array}$ \\
\hline Dowex 550A LC & Styrene-DVB, Gel & $-\mathrm{N}^{+} \mathrm{R}_{3}$ & $0.3-1.2$ & 63 & $0-14$ & 60 \\
Indion-930A & Crosslinked Polyacrylic & $-\mathrm{N}^{+} \mathrm{R}_{3}$ & $0.3-1.2$ & 66 & $0-10$ & 80 \\
\hline
\end{tabular}

\subsection{Radioactive Tracer Isotopes}

The radioisotope ${ }^{131} \mathrm{I}$ and ${ }^{82} \mathrm{Br}$ used in the present experimental work was obtained from Board of Radiation and Isotope Technology (BRIT), Mumbai, India. Details regarding the isotopes used in the present experimental work are given in Table 2.

Table 2. Properties of ${ }^{131} \mathrm{I}_{\text {and }}{ }^{82} \mathrm{Br}$ tracer isotopes ${ }^{1}$

\begin{tabular}{cccccc}
\hline Isotopes & Half-life & $\begin{array}{c}\text { Radioactivity } \\
/ \mathrm{mCi}\end{array}$ & $\begin{array}{c}\gamma \text { - energy } \\
/ \mathrm{MeV}\end{array}$ & $\begin{array}{c}\text { Chemical } \\
\text { form }\end{array}$ & $\begin{array}{c}\text { Physical } \\
\text { form }\end{array}$ \\
\hline${ }^{131} \mathrm{I}$ & $8.04 \mathrm{~d}$ & 5 & 0.36 & Iodide* $^{*}$ & Aqueous \\
${ }^{82} \mathrm{Br}$ & $36 \mathrm{~h}$ & 5 & 0.55 & Bromide** & Aqueous \\
\hline * Sodium iodide in dilute sodium sulphite. & & & & \\
** Ammonium bromide in dilute ammonium hydroxide. & & &
\end{tabular}

\subsection{Study on kinetics of iodide ion-isotopic exchange reaction}

In a stoppered bottle $250 \mathrm{~mL}(V)$ of $0.001 \mathrm{~mol} / \mathrm{L}$ iodide ion solution was labeled with diluted ${ }^{131} \mathrm{I}$ radioactive solution using a micro syringe, such that $1.0 \mathrm{~mL}$ of labeled solution has a radioactivity of 
around 15,000 cpm (counts per minute) when measured with $\gamma$-ray spectrometer having NaI (Tl) scintillation detector. Since only about $50-100 \mu \mathrm{L}$ of the radioactive iodide ion solution was required for labeling the solution, its concentration will remain unchanged, which was further confirmed by potentiometer titration against $\mathrm{AgNO}_{3}$ solution. The above labeled solution of known initial activity $\left(A_{i}\right)$ was kept in a thermostat adjusted to $30.0{ }^{\circ} \mathrm{C}$. The swelled and conditioned dry ion exchange resins in iodide form weighing exactly $1.000 \mathrm{~g}(\mathrm{~m})$ were transferred quickly into this labeled solution which was vigorously stirred by using mechanical stirrer and the activity in cpm of $1.0 \mathrm{~mL}$ of solution was measured. The solution was transferred back to the same bottle containing labeled solution after measuring activity. The iodide ion-isotopic exchange reaction can be represented as:

$\mathrm{R}-\mathrm{I}+\mathrm{I}^{*^{-}}{ }_{(\mathrm{aq} .)} \rightleftharpoons \mathrm{R}-\mathrm{I}^{*}+\mathrm{I}_{(\text {aq. })}^{-}$

Here R-I represents ion exchange resin in iodide form; $\mathrm{I}^{*^{-}}$(aq.) represents aqueous iodide ion solution labeled with ${ }^{131}$ I radiotracer isotope. The activity of solution was measured at a fixed interval of every $2.0 \mathrm{~min}$. The final activity $\left(A_{f}\right)$ of the solution was also measured after $3 \mathrm{~h}$ which was sufficient time to attain the equilibrium ${ }^{10-14}$. The activity measured at various time intervals was corrected for background counts. Similar experiments were carried out by equilibrating separately $1.000 \mathrm{~g}$ of ion exchange resin in iodide form with labeled iodide ion solution of four different concentrations ranging up to $0.004 \mathrm{~mol} / \mathrm{L}$ at a constant temperature of $30.0{ }^{\circ} \mathrm{C}$. The same experimental sets were repeated for higher temperatures up to $45.0^{\circ} \mathrm{C}$.

\subsection{Study on kinetics of bromide ion-isotopic exchange reaction}

The experiment was also performed to study the kinetics of bromide ion- isotopic exchange reaction by equilibrating $1.000 \mathrm{~g}$ of ion exchange resin in bromide form with labeled bromide ion solution in the same concentration and temperature range as above. The labeling of bromide ion solution was done by using ${ }^{82} \mathrm{Br}$ as a radioactive tracer isotope for which the same procedure as explained above was followed. The bromide ion-isotopic exchange reaction can be represented as:

$\mathrm{R}-\mathrm{Br}+\mathrm{Br}^{*^{-}}{ }_{\text {(aq.) }} \rightleftharpoons \mathrm{R}-\mathrm{Br}^{*}+\mathrm{Br}^{-}{ }_{(\text {aq. }}$

Here $\mathrm{R}-\mathrm{Br}$ represents ion exchange resin in bromide form; $\mathrm{Br}^{*^{-}}{ }_{(\mathrm{aq} .)}$ represents aqueous bromide ion solution labeled with ${ }^{82} \mathrm{Br}$ radiotracer isotope.

\section{Results and Discussion}

\subsection{Comparative study of ion-isotopic exchange reactions}

In the present investigation, it was observed that due to the rapid ion-isotopic exchange reaction taking place, the activity of solution decreases rapidly initially, then due to the slow exchange the activity of the solution decreases slowly and finally remains nearly constant. Preliminary studies show that the above exchange reactions are of first order ${ }^{10-14}$. Therefore logarithm of activity when plotted against time gives a composite curve in which the activity initially decreases sharply and thereafter very slowly giving nearly straight line (Figure 1), evidently rapid and slow ion-isotopic exchange reactions were occurring simultaneously ${ }^{10-14}$. Now the straight line was extrapolated back to zero time. The extrapolated portion represents the contribution of slow process to the total activity which now includes rapid process also. The activity due to slow process was subtracted from the total activity at various time intervals. The difference gives the activity due to rapid process only. From the activity exchanged due to rapid process at various time intervals, the specific reaction rates $(k)$ of rapid ion-isotopic exchange reaction were calculated. The amount of iodide / bromide ions exchanged $(\mathrm{mmol})$ on the resin were obtained from the initial and final activity of solution and the amount of exchangeable ions in $250 \mathrm{~mL}$ of solution. From the amount of ions exchanged on the resin (mmol) and the specific reaction rates $\left(\mathrm{min}^{-1}\right)$, the initial rate of ion exchanged $(\mathrm{mmol} / \mathrm{min})$ was calculated. 


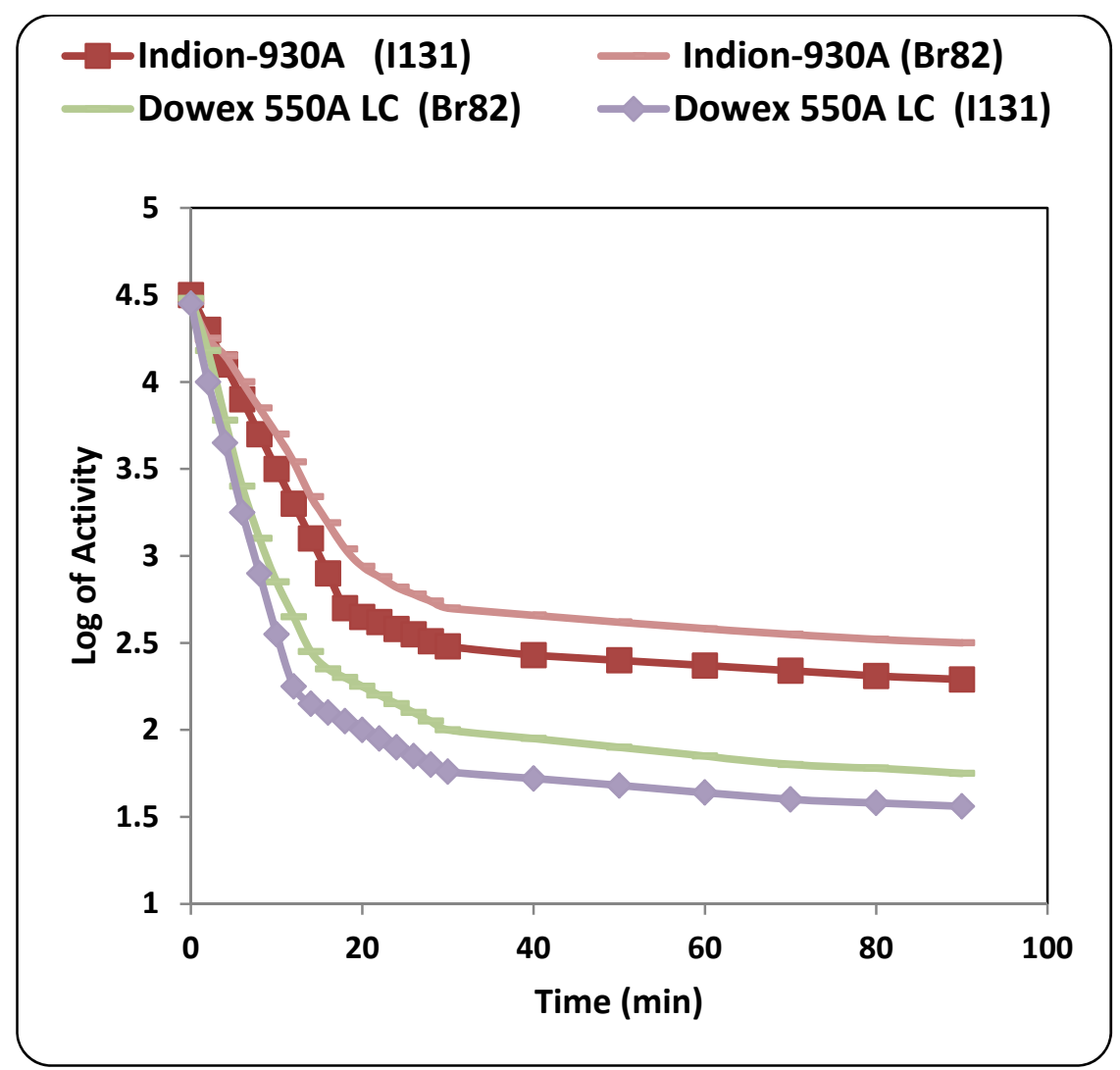

Fig. 1. Kinetics of Ion-Isotopic Exchange Reactions

Amount of ion exchange resin $=1.000 \mathrm{~g}$, Concentration of labeled exchangeable ionic solution $=0.002 \mathrm{~mol} / \mathrm{L}$, Volume of labeled ionic solution $=250 \mathrm{~mL}$, Temperature $=35.0{ }^{\circ} \mathrm{C}$

Because of larger solvated size of bromide ions as compared to that of iodide ions, it was observed that the exchange of bromide ions occurs at the slower rate than that of iodide ions. Hence under identical experimental conditions, the values of specific reaction rate $\left(\mathrm{min}^{-1}\right)$, amount of ion exchanged (mmol) and initial rate of ion exchange $(\mathrm{mmol} / \mathrm{min})$ are calculated to be lower for bromide ion-isotopic exchange reaction than that for iodide ion-isotopic exchange reaction as summarized in Tables 3 and 4. For both bromide and iodide ion-isotopic exchange reactions, under identical experimental conditions, the values of specific reaction rate increases with increase in the concentration of iodide and bromide ions in solution from $0.001 \mathrm{~mol} / \mathrm{L}$ to $0.004 \mathrm{~mol} / \mathrm{L}$ (Table 3). However, with rise in temperature from $30.0^{\circ} \mathrm{C}$ to $45.0^{\circ} \mathrm{C}$, the specific reaction rate was observed to decrease (Table 4). Thus in case of Dowex 550A LC at $35.0^{\circ} \mathrm{C}$ when the concentration of iodide and bromide ions in solution increases from $0.001 \mathrm{~mol} / \mathrm{L}$ to $0.004 \mathrm{~mol} / \mathrm{L}$, the specific reaction rate values for iodide ion-isotopic exchange increases from 0.256 to $0.301 \mathrm{~min}^{-1}$, while for bromide ion-isotopic exchange the values increases from 0.216 to $0.258 \mathrm{~min}^{-1}$. Similarly in case of Indion-930A, under identical experimental conditions, the values for iodide ion-isotopic exchange increases from 0.144 to $0.178 \mathrm{~min}^{-1}$, while for bromide ion-isotopic exchange the values increases from 0.113 to $0.142 \mathrm{~min}^{-1}$. However when the concentration of iodide and bromide ions in solution is kept constant at 0.002 $\mathrm{mol} / \mathrm{L}$ and temperature is raised from $30.0{ }^{0} \mathrm{C}$ to $45.0{ }^{\circ} \mathrm{C}$, in case of Dowex $550 \mathrm{~A}$ LC the specific reaction rate values for iodide ion-isotopic exchange decreases from 0.280 to $0.249 \mathrm{~min}^{-1}$, while for bromide ion-isotopic exchange the values decreases from 0.239 to $0.207 \mathrm{~min}^{-1}$. Similarly in case of Indion-930A, under identical experimental conditions, the specific reaction rate values for iodide ionisotopic exchange decreases from 0.167 to $0.131 \mathrm{~min}^{-1}$, while for bromide ion-isotopic exchange the values decreases from 0.130 to $0.112 \mathrm{~min}^{-1}$. From the results, it appears that iodide ions exchange at the faster rate as compared to that of bromide ions which was related to the extent of solvation (Tables 3 and 4). 
Table 3. Concentration effect on Ion-Isotopic Exchange Reactions

\begin{tabular}{|c|c|c|c|c|c|c|c|c|c|c|c|c|c|c|c|c|c|}
\hline \multirow[b]{3}{*}{ 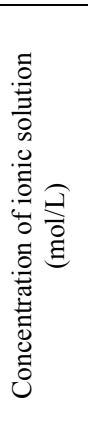 } & \multirow{3}{*}{ 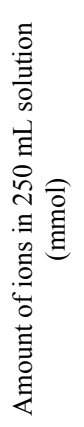 } & \multicolumn{8}{|c|}{ REACTION -1 } & \multicolumn{8}{|c|}{ REACTION -2 } \\
\hline & & \multicolumn{4}{|c|}{ Dowex-550A LC } & \multicolumn{4}{|c|}{ Indion-930A } & \multicolumn{4}{|c|}{ Dowex-550A LC } & \multicolumn{4}{|c|}{ Indion-930A } \\
\hline & & 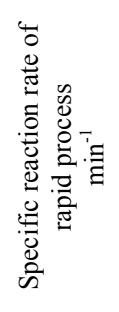 & 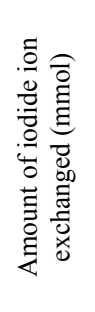 & 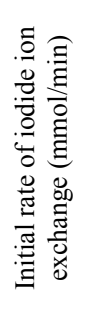 & $\begin{array}{l}\vec{I} \\
00 \\
0 \\
\Theta\end{array}$ & 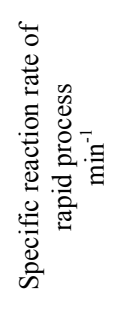 & 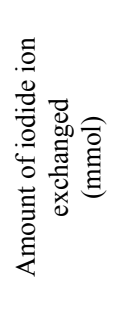 & 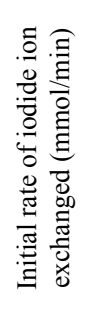 & $\begin{array}{l}\vec{I} \\
00 \\
0 \\
9\end{array}$ & 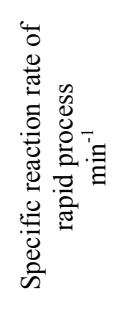 & 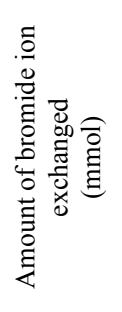 & 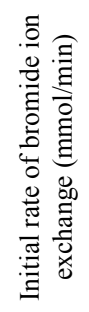 & $\begin{array}{l}\vec{y} \\
00 \\
0 \\
9\end{array}$ & 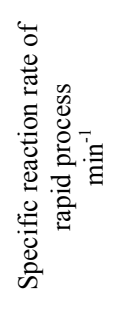 & 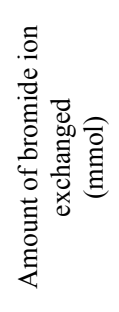 & 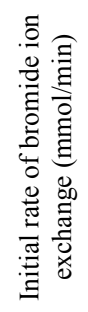 & $\begin{array}{l}\vec{y} \\
00 \\
0 \\
0\end{array}$ \\
\hline 0.001 & 0.250 & 0.256 & 0.165 & 0.042 & 10.6 & 0.144 & 0.118 & 0.017 & 6.8 & 0.216 & 0.137 & 0.030 & 9.3 & 0.113 & 0.099 & 0.011 & 3.0 \\
\hline 0.002 & 0.500 & 0.270 & 0.342 & 0.092 & 11.8 & 0.156 & 0.241 & 0.038 & 7.4 & 0.228 & 0.283 & 0.064 & 10.4 & 0.125 & 0.206 & 0.026 & 4.0 \\
\hline 0.003 & 0.750 & 0.282 & 0.527 & 0.148 & 13.0 & 0.169 & 0.367 & 0.062 & 8.0 & 0.236 & 0.435 & 0.103 & 10.8 & 0.133 & 0.321 & 0.043 & 4.5 \\
\hline 0.004 & 1.000 & 0.301 & 0.724 & 0.218 & 13.5 & 0.178 & 0.495 & 0.088 & 8.4 & 0.258 & 0.591 & 0.152 & 11.5 & 0.142 & 0.441 & 0.063 & 5.1 \\
\hline
\end{tabular}

Table 4. Temperature effect on Ion-Isotopic Exchange Reactions

$$
\text { REACTION -1 }
$$

REACTION -2

\begin{tabular}{|c|c|c|c|c|c|c|c|c|c|c|c|c|c|c|c|c|}
\hline \multirow[b]{2}{*}{ 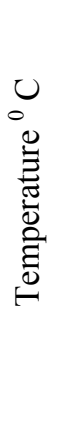 } & \multicolumn{4}{|c|}{ Dowex-550A LC } & \multicolumn{4}{|c|}{ Indion-930A } & \multicolumn{4}{|c|}{ Dowex-550A LC } & \multicolumn{4}{|c|}{ Indion-930A } \\
\hline & 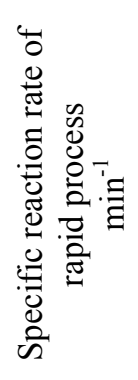 & 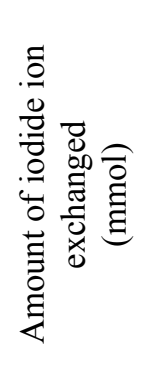 & 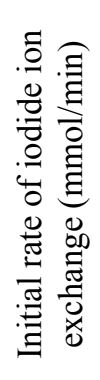 & $\begin{array}{l}\vec{U} \\
00 \\
0 \\
1\end{array}$ & 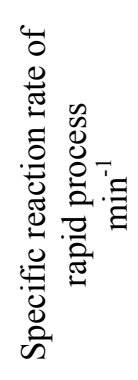 & 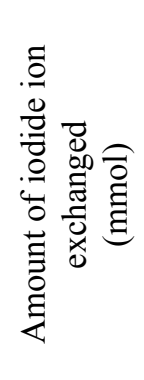 & 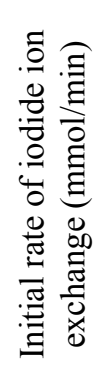 & $\begin{array}{l}\vec{y} \\
0 \\
0 \\
1 \\
1\end{array}$ & 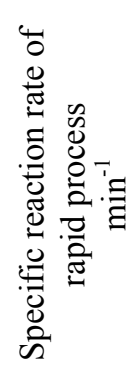 & 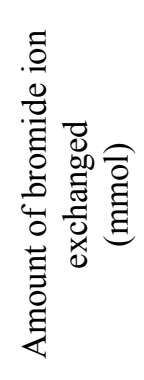 & 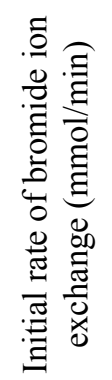 & $\begin{array}{l}\vec{U} \\
00 \\
0 \\
0\end{array}$ & 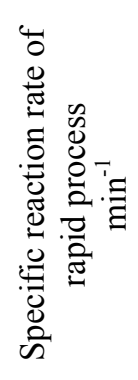 & 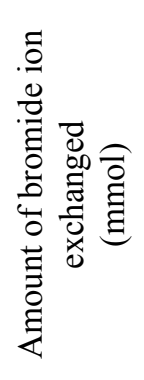 & 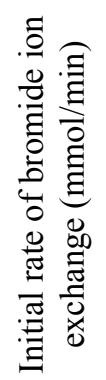 & $\begin{array}{l}7 \\
0 \\
0 \\
\varrho\end{array}$ \\
\hline 30.0 & 0.280 & 0.351 & 0.098 & & 0.167 & 0.245 & 0.041 & & 0.239 & 0.294 & 0.070 & & 0.130 & 0.217 & 0.028 & 4.8 \\
\hline 35.0 & 0.270 & 0.342 & 0.092 & 11.8 & 0.156 & 0.241 & 0.038 & 7.4 & 0.228 & 0.283 & 0.064 & 10.4 & 0.125 & 0.206 & 0.026 & 4.0 \\
\hline 40.0 & 0.260 & 0.336 & 0.087 & 11.5 & 0.143 & 0.236 & 0.034 & 6.7 & 0.215 & 0.279 & 0.060 & 9.9 & 0.118 & 0.198 & 0.023 & 3.6 \\
\hline 45.0 & 0.249 & 0.328 & 0.082 & 11.0 & 0.131 & 0.233 & 0.031 & 6.2 & 0.207 & 0.263 & 0.054 & 9.3 & 0.112 & 0.187 & 0.021 & 3.2 \\
\hline
\end{tabular}

Amount of ion exchange resin $=1.000 \mathrm{~g}$

Concentration of labeled exchangeable ionic solution $=0.002 \mathrm{~mol} / \mathrm{L}$

Volume of labeled ionic solution $=250 \mathrm{~mL}$
Amount of exchangeable ions in $250 \mathrm{~mL}$ labeled solution $=0.500 \mathrm{mmol}$ 
From the knowledge of $A_{i}, A_{f}$, volume of the exchangeable ionic solution ( $V$ ) and mass of ion exchange resin $(m)$, the $K_{d}$ value was calculated by the equation

$K_{d}=\left[\left(A_{i}-A_{f}\right) / A_{f}\right] \times V / m$

Previous studies ${ }^{15,16}$ on halide ion distribution coefficient on strong and weak basic anion exchange resins indicate that the selectivity coefficient between halide ions increased at higher electrolyte concentrations. Adachi et al. ${ }^{17}$ observed that the swelling pressure of the resin decreased at higher solute concentrations resulting in larger $K_{d}$ values. The temperature dependence of $K_{d}$ values on cation exchange resin was studied by Shuji et al. ${ }^{18}$; were they observed that the values of $\mathrm{K}_{\mathrm{d}}$ increased with fall in temperature. The present experimental results also indicates that the $\mathrm{K}_{\mathrm{d}}$ values for bromide and iodide ions increases with increase in ionic concentration of the external solution, however with rise in temperature the $\mathrm{K}_{d}$ values were found to decrease. Thus in case of Dowex 550A $\mathrm{LC}$ at $35.0^{\circ} \mathrm{C}$ when the concentration of iodide and bromide ions in solution increases from 0.001 $\mathrm{mol} / \mathrm{L}$ to $0.004 \mathrm{~mol} / \mathrm{L}$, the $\log \mathrm{K}_{\mathrm{d}}$ values for iodide ions increases from 10.6 to 13.5 , while for bromide ions the values increases from 9.3 to 11.5. Similarly in case of Indion-930A, under identical experimental conditions, the $\log \mathrm{K}_{\mathrm{d}}$ values for iodide ions increases from 6.8 to 8.4, while for bromide ions the values increases from 3.0 to 5.1. However when the concentration of iodide and bromide ions in solution is kept constant at $0.002 \mathrm{~mol} / \mathrm{L}$ and temperature is raised from $30.0{ }^{0} \mathrm{C}$ to $45.0{ }^{\circ} \mathrm{C}$, in case of Dowex 550A LC the $\log \mathrm{K}_{\mathrm{d}}$ values for iodide ions decreases from 12.0 to 11.0 , while for bromide ions the values decreases from 10.9 to 9.3. Similarly in case of Indion-930A, under identical experimental conditions, the $\log \mathrm{K}_{\mathrm{d}}$ values for iodide ions decreases from 8.0 to 6.2 , while for bromide ions the values decreases from 4.8 to 3.2. It was also observed that the $K_{d}$ values for iodide ion-isotopic exchange reaction were calculated to be higher than that for bromide ion-isotopic exchange reaction (Tables 3 and 4).

\subsection{Comparative study of anion exchange resins}

From the Table 3 and Table 4, it is observed that for iodide ion-isotopic exchange reaction by using Dowex 550A LC resin, the values of specific reaction rate $\left(\mathrm{min}^{-1}\right)$, amount of iodide ion exchanged (mmol), initial rate of iodide ion exchange $(\mathrm{mmol} / \mathrm{min})$ and $\log \mathrm{K}_{\mathrm{d}}$ were $0.270,0.342$, 0.092 and 11.8 respectively, which was higher than $0.156,0.241,0.038$ and 7.4 respectively as that obtained by using Indion-930A resins under identical experimental conditions of $35.0^{\circ} \mathrm{C}, 1.000 \mathrm{~g}$ of ion exchange resins and $0.002 \mathrm{~mol} / \mathrm{L}$ labeled iodide ion solution. The identical trend was observed for the two resins during bromide ion-isotopic exchange reaction.

From Table 3, it is observed that at a constant temperature of $35.0{ }^{0} \mathrm{C}$, as the concentration of labeled iodide ion solution increases from $0.001 \mathrm{~mol} / \mathrm{L}$ to $0.004 \mathrm{~mol} / \mathrm{L}$, the percentage of iodide ions exchanged increases from $66.00 \%$ to $72.40 \%$ using Dowex 550A LC resins and from $47.20 \%$ to $49.50 \%$ using Indion-930A resins. Similarly in case of bromide ion-isotopic exchange reactions under identical experimental conditions, the percentage of bromide ions exchanged increases from $54.90 \%$ to $59.10 \%$ using Dowex 550A LC resin and from $39.60 \%$ to $44.10 \%$ using Indion-930A resin. The effect of ionic concentration on percentage of ions exchanged is graphically represented in Fig. 2. From Table 4, it is observed that for $0.002 \mathrm{~mol} / \mathrm{L}$ labeled iodide ion solution, as the temperature increases from $30.0{ }^{0} \mathrm{C}$ to $45.0{ }^{0} \mathrm{C}$, the percentage of iodide ions exchanged decreases from $70.10 \%$ to $65.50 \%$ using Dowex $550 \mathrm{~A}$ LC resins and from $49.00 \%$ to $46.60 \%$ using Indion930A resins. Similarly under identical experimental conditions, in case of bromide ion-isotopic exchange reactions, the percentage of bromide ions exchanged decreases from $58.70 \%$ to $52.50 \%$ using Dowex 550A LC resin and from $43.40 \%$ to $37.40 \%$ using Indion-930A resin. The effect of temperature on percentage of ions exchanged is graphically represented in Fig. 3. 


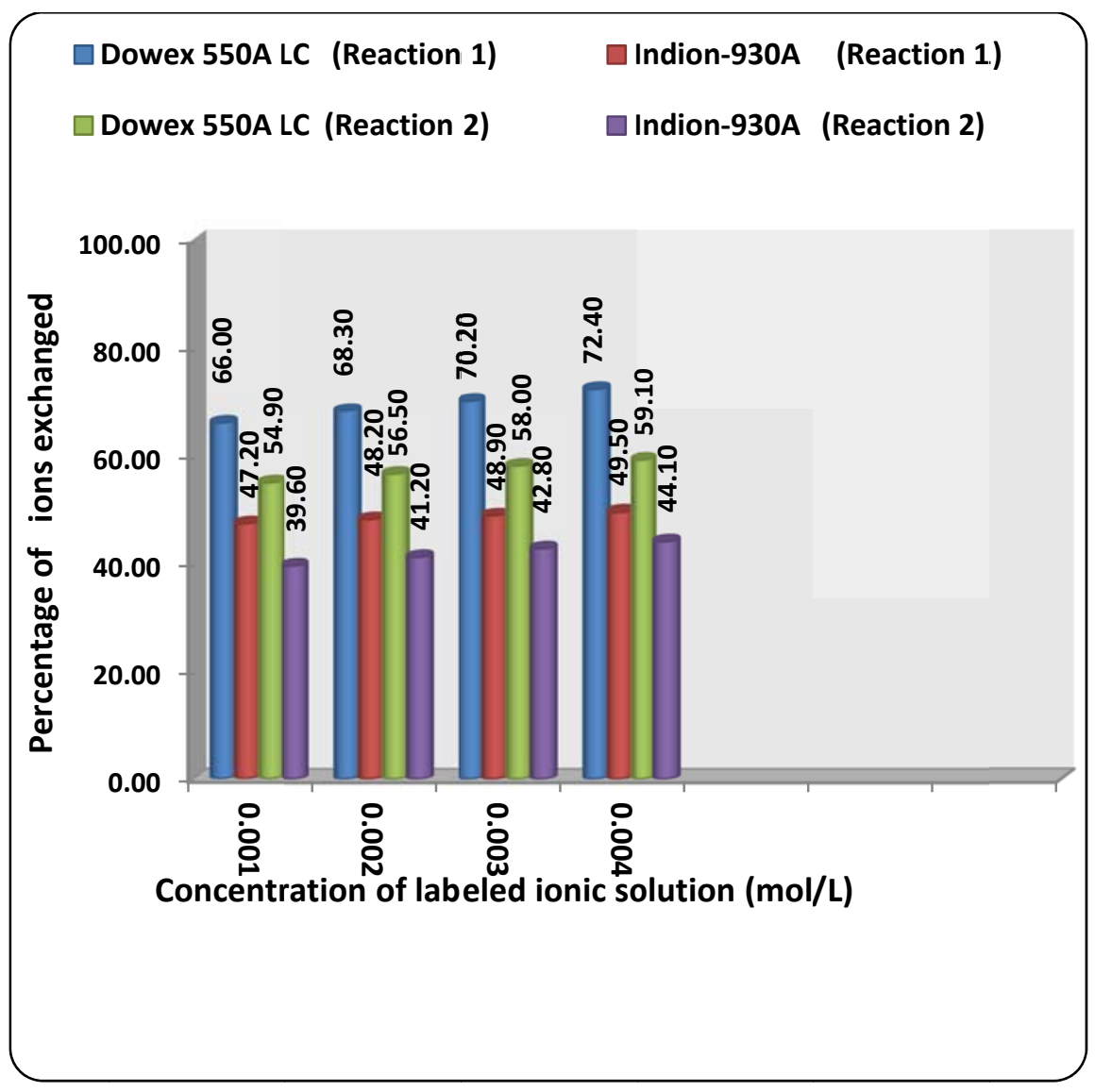

Fig. 2. Variation in Percentage Ions Exchanged with Concentration of Labeled Ionic Solution Amount of ion exchange resin $=1.000$ g, Volume of labeled ionic solution $=250 \mathrm{~mL}$, Temperature $=35.0{ }^{\circ} \mathrm{C}$

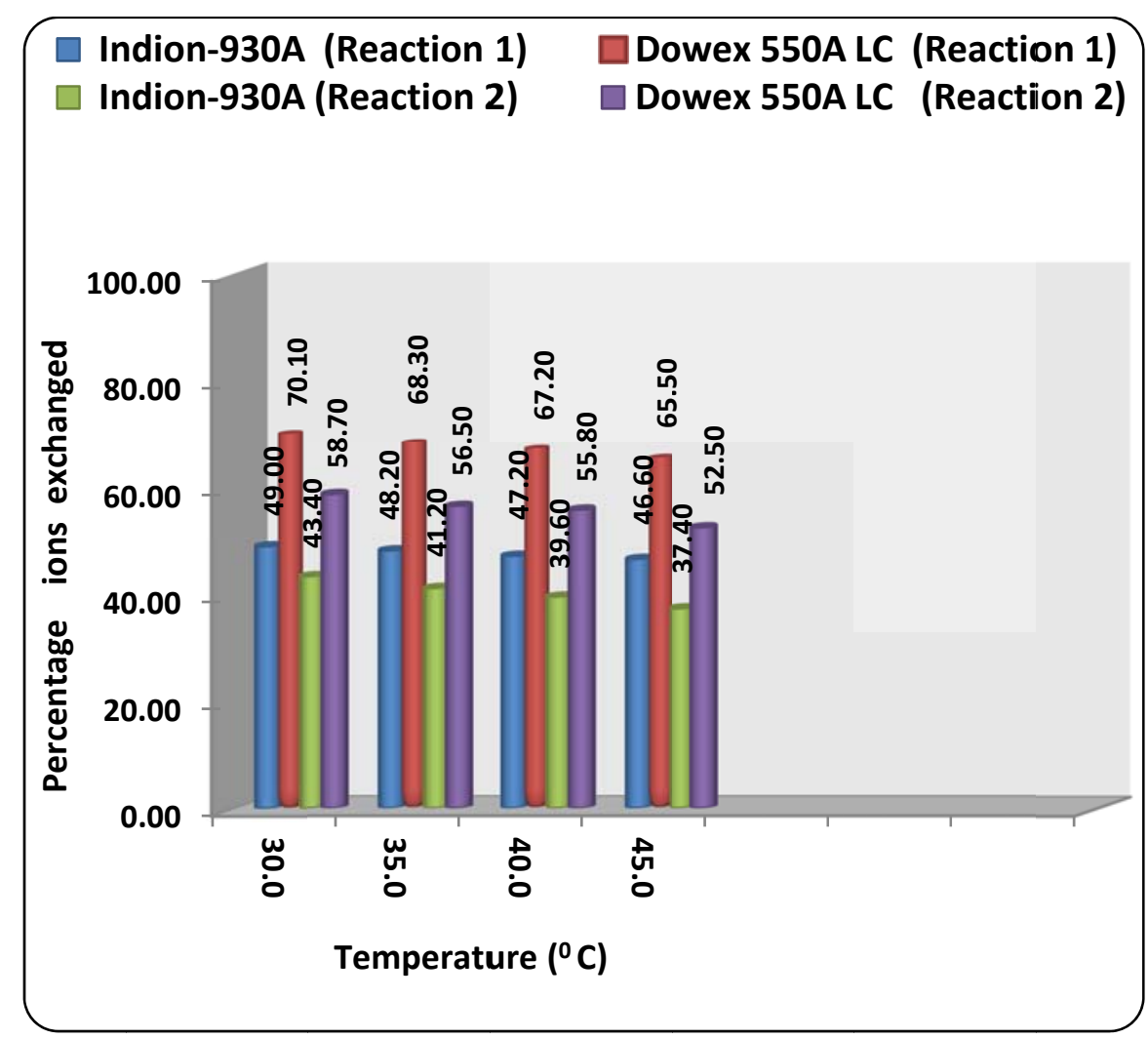

Fig. 3. Variation in Percentage Ions Exchanged with Temperature of Labeled Ionic Solution Amount of ion exchange: resin $=1.000 \mathrm{~g}$, Concentration of labeled exchangeable ionic solution $=0.002 \mathrm{~mol} / \mathrm{L}$, Volume of labeled ionic solution $=250 \mathrm{~mL}$, Amount of exchangeable ions in $250 \mathrm{~mL}$ labeled solution $=0.500 \mathrm{mmol}$ 
The overall results indicate that under identical experimental conditions, as compared to Indion930A resins, Dowex 550A LC resins shows higher percentage of ions exchanged. Thus Dowex 550A LC resins show superior performance over Indion-930A resins under identical operational parameters.

\subsection{Statistical Correlations}

The results of present investigation show a strong positive linear correlation between amount of ions exchanged and concentration of ionic solution (Fig. 4, Fig. 5). In case of iodide ion-isotopic exchange reaction, the values of correlation coefficient $(r)$ were calculated as 0.9997 and 1.0000 for both Dowex 550A LC and Indion-930A resins respectively, while for bromide ion-isotopic exchange reaction, the values of $r$ was calculated as 0.9999 and 0.9997 respectively for the two resins.
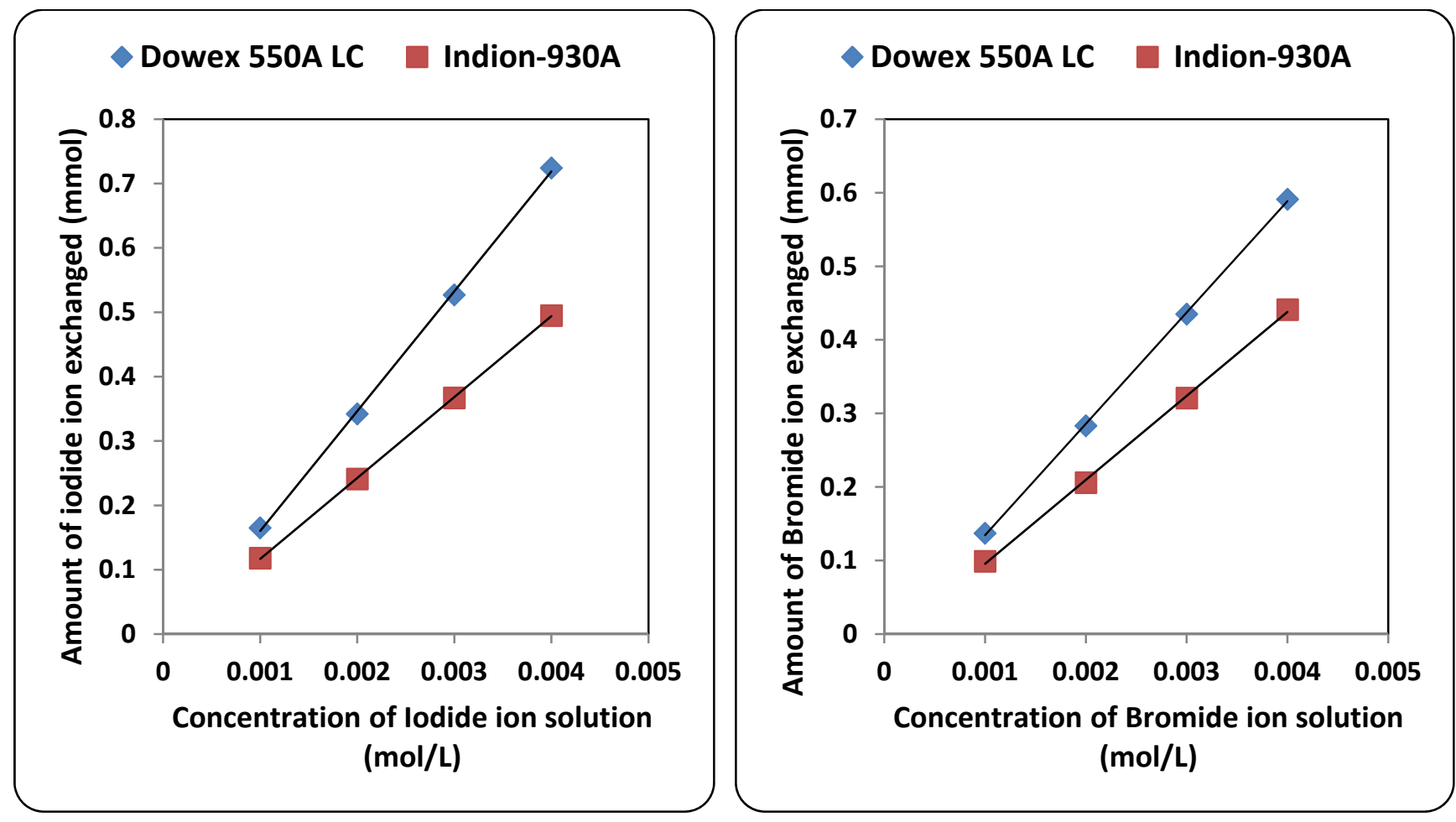

Fig. 4. Correlation between concentration of iodide ion solution and amount of iodide ion exchanged Amount of ion exchange resin $=1.000 \mathrm{~g}$, Volume of labeled ionic solution $=250 \mathrm{~mL}$, Temperature $=35.0{ }^{0} \mathrm{C}$

Correlation coefficient (r) for Dowex-550A LC $=0.9997$

Correlation coefficient $(r)$ for Indion-930A $=1.0000$
Fig. 5. Correlation between concentration of bromide ion solution and amount of bromide ion exchanged Amount of ion exchange resin $=1.000 \mathrm{~g}$, Volume of labeled ionic solution $=250 \mathrm{~mL}$, Temperature $=35.00 \mathrm{C}$

Correlation coefficient ( $r$ ) for Dowex-550A LC $=0.9999$ Correlation coefficient $(\mathrm{r})$ for Indion-930A $=0.9997$

There also exist a strong negative correlation between amount of ions exchanged and temperature of exchanging medium (Figures 6,7). In case of iodide ion-isotopic exchange reactions the values of $r$ calculated for Dowex 550A LC and Indion-930A resins were -0.9973 and -0.9959 respectively. Similarly in case of bromide ion-isotopic exchange reactions the $r$ values calculated were -0.9751 and -0.9981 respectively for both the resins.

\section{Conclusions}

The experimental work carried out in the present investigation will help to standardize the operational process parameters so as to improve the performance of selected ion exchange resins. The radioactive tracer technique used here can also be applied further for characterization of different nuclear as well as non-nuclear grade ion exchange resins. 


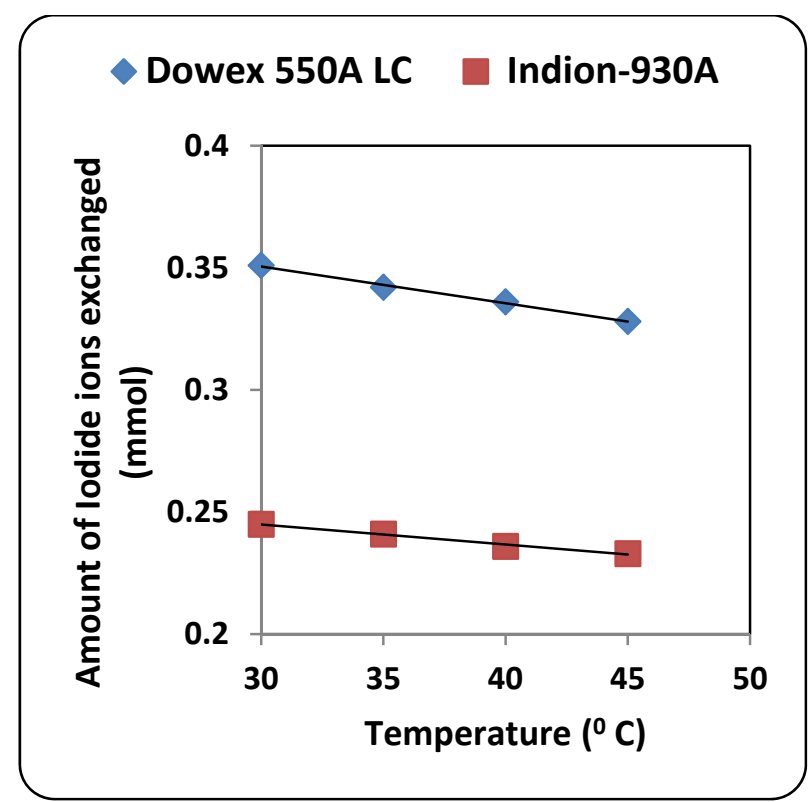

Fig. 6. Correlation between Temperature of exchanging medium and amount of iodide ion exchanged Amount of ion exchange resin $=1.000 \mathrm{~g}$, Concentration of labeled exchangeable ionic solution $=0.002 \mathrm{~mol} / \mathrm{L}$, Volume of labeled ionic solution $=250 \mathrm{~mL}$, Amount of exchangeable ions in $250 \mathrm{~mL}$ labeled solution $=0.500 \mathrm{mmol}$

Correlation coefficient (r) for Dowex-550A LC $=-0.9973$

Correlation coefficient $(r)$ for Indion-930A $=-0.9959$
Dowex 550A LC $\square$ Indion-930A

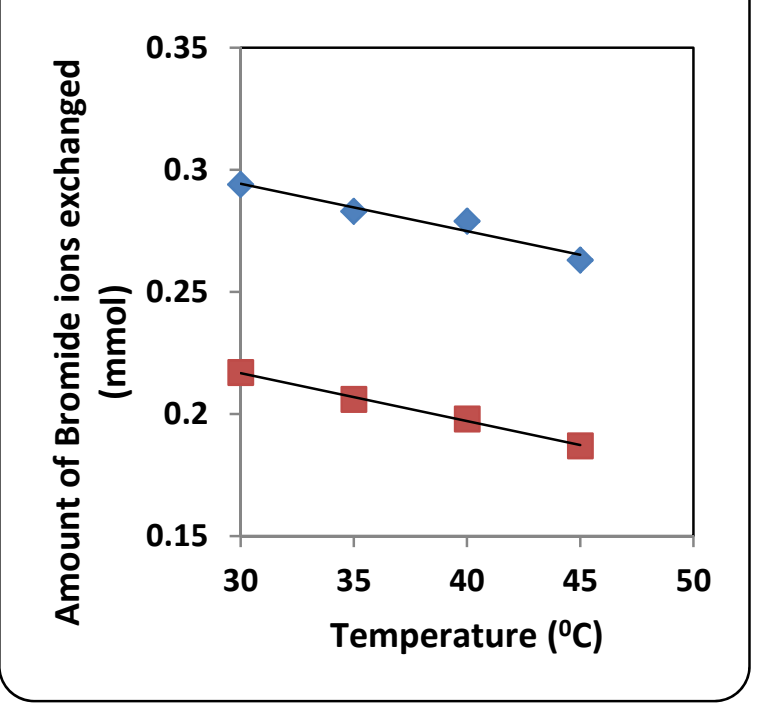

Fig. 7. Correlation between Temperature of exchanging medium and amount of bromide ion exchanged Amount of ion exchange resin $=1.000 \mathrm{~g}$, Concentration of labeled exchangeable ionic solution $=0.002 \mathrm{~mol} / \mathrm{L}$, Volume of labeled ionic solution $=250 \mathrm{~mL}$, Amount of exchangeable ions in $250 \mathrm{~mL}$ labeled solution $=0.500 \mathrm{mmol}$ Correlation coefficient (r) for Dowex-550A LC $=-0.9751$ Correlation coefficient $(r)$ for Indion-930A $=-0.9981$

\section{Acknowledgements}

The author is thankful to Professor Dr. R.S. Lokhande (Retired) for his valuable help and support by providing the required facilities so as to carry out the experimental work in Radiochemistry Laboratory, Department of Chemistry, University of Mumbai, Vidyanagari, Mumbai -58.

\section{References}

1. Sood D.D., Reddy A.V.R., and Ramamoorthy N. (2004) Applications of radioisotopes in physicochemical investigations, in: Fundamentals of Radiochemistry, Indian Association of Nuclear Chemists and Allied Scientists (IANCAS), 253-263.

2. Radiotracer Applications in Industry - A Guidebook (2004) Technical Reports Series No.423, IAEA, Vienna.

3. Clark M.W., Harrison J.J., and Payne, T.E. (2011) The pH-dependence and reversibility of uranium and thorium binding on a modified bauxite refinery residue using isotopic exchange techniques. J. Colloid Interf. Sci., 356, 699-705.

4. Dagadu, C.P.K., Akaho, E.H.K., Danso, K.A., Stegowski, Z., and Furman, L. (2012) Radiotracer investigation in gold leaching tanks. Appl. Radiat. Isotopes, 70, 156-161.

5. Koron, N., Bratkic, A., Ribeiro Guevara, S., Vahcic, M., and Horvat, M. (2012) Mercury methylation and reduction potentials in marine water: An improved methodology using $197 \mathrm{Hg}$ radiotracer. Appl. Radiat. Isotopes, 70, 46-50 (2012).

6. Meng, X., and Weiguo, L. (2011) An improved method of ion exchange for nitrogen isotope analysis of water nitrate. Anal. Chim. Acta, 686, 107-114

7. Randriamanantsoa, L., Morel, C., Rabeharisoa, L., Douzet, J.M., Jansa, J., and Frossard, E. (2013) Can the isotopic exchange kinetic method be used in soils with a very low water extractable phosphate content and a high sorbing capacity for phosphate ions? Geoderma, 200, 120-129. 
8. Mochizuki, K., Munakata,K., Wajima,T., Hara,K., Wada,K., Shinozaki,T., Takeishi,T., Knitter, R., Bekris, N., and Okuno, K. (2010) Study of isotope exchange reactions on ceramic breeder materials deposited with noble metal. Fusion Eng. Des., 85, 1185-1189.

9. Li, Z., Chansaenpak, K., Liu, S., Wade, C.R., Conti, P.S., and Gabbaï, F.P. (2012) Harvesting 18Ffluoride ions in water via direct $18 \mathrm{~F}-19 \mathrm{~F}$ isotopic exchange: radiofluorination of zwitterionic aryltrifluoroborates and in vivo stability studies. Med. Chem. Comm., 3, 1305-1308.

10. Singare, P.U., and Lokhande, R.S. (2012) Studies on ion-isotopic exchange reactions using nuclear grade ion exchange resins. Ionics, 18, 351-357.

11.Lokhande, R.S., and Singare, P.U. (2007) Comparative study on ion-isotopic exchange reaction kinetics by application of tracer technique. Radiochim. Acta, 95, 173-176.

12.Lokhande, R.S., Singare, P.U., and Patil, V.V. (2008) Application of radioactive tracer technique to study the kinetics and mechanism of reversible ion-isotopic exchange reaction using strongly basic anion exchange resin Indion -850. Radiochemistry, 50, 638-641.

13. Lokhande, R.S., and Singare, P.U. (2008) Comparative study on iodide and bromide ion-isotopic exchange reactions by application of radioactive tracer technique. J. Porous Mater., 15, 253-258.

14. Lokhande, R. S., Singare, P. U., and Dole, M. H. (2006) Comparative study on bromide and iodide ion-isotopic exchange reactions using strongly basic anion exchange resin Duolite A-113. J. Nuclear and Radiochemical Sciences, 7, 29-32.

15. Heumann, K.G., and Baier, K. (1982) Chloride distribution coefficient on strongly basic anionexchange resin: Dependence on co-ion in alkali fluoride solutions. Chromatographia, 15, 701-703.

16. Singare, P.U., Lokhande, R.S., Patil, V.V., Prabhavalkar, T. S., and Tiwari, S. R. D. (2010) Study on distribution coefficient of bromide ions from aqueous solution on ion exchange resins Indion850, Indion-860 and Indion FF-IP. Eur. J. Chem., 1, 47-49.

17. Adachi, S., Mizuno, T., and Matsuno, R. (1995) Concentration dependence of the distribution coefficient of maltooligosaccharides on a cation-exchange resin. J. Chromatogr. A, 708, 177-183.

18. Shuji, A., Takcshi, M., and Ryuichi, M. (1996) Temperature dependence of the distribution coefficient of maltooligosaccharides on cation-exchange resin in $\mathrm{Na}+$ form. Biosci. Biotechnol. Biochem., 60, 338-340. 